\title{
Editorial: Marine Observations and Society: Pathways to Improve Public Engagement and the Science-Policy Nexus
}

\author{
T. Zielinski ${ }^{1 *}, K$. Evans $^{2}$ and J. Seys ${ }^{3}$ \\ ${ }^{1}$ Institute of Oceanology Polish Academy of Sciences, Sopot, Poland, ${ }^{2}$ Commonwealth Scientific and Industrial Research \\ Organisation (CSIRO), Canberra, ACT, Australia, ${ }^{3}$ Flanders Marine Institute (VLIZ), Ostend, Belgium
}

Keywords: marine observations, ocean science communication and education, SDGS, ocean literacy, citizen science, science, policy and governance

\section{Editorial on the Research Topic}

Marine Observations and Society: Pathways to Improve Public Engagement and the SciencePolicy Nexus

\section{OPEN ACCESS}

Edited and reviewed by: Tarla Rai Peterson, The University of Texas at El Paso, United States

${ }^{*}$ Correspondence: T. Zielinski tymon@iopan.pl

Specialty section: This article was submitted to

Science and Environmental Communication,

a section of the journal Frontiers in Environmental Science

Received: 05 October 2021 Accepted: 21 October 2021 Published: 02 November 2021

Citation:

Zielinski T, Evans K and Seys J (2021)

Editorial: Marine Observations and Society: Pathways to Improve Public

Engagement and the Science-

Policy Nexus.

Front. Environ. Sci. 9:789942. doi: 10.3389/fenvs.2021.789942
Climate change, and the resulting global warming and acidification of the ocean is causing change to marine environments (United Nations, 2017; IPCC 2021) with serious implications for global ecosystems, food security and ocean economies (Allison and Bassett 2015; Pörtner et al., 2019). To ensure a sustainable future for all, there is a need to understand these changes and their impacts on the provision of services from the marine environment. This will also require the identification of knowledge gaps and the capacity needed to develop effective and sustained ocean observation systems that support the development of relevant responses (Evans et al., 2019; Wisz et al., 2020).

Improved societal understanding of the services provided by the ocean, and how humans affect the ocean are at the core of the development and implementation of sustainable decision-making and is particularly important within the context of achieving the globally agreed sustainability targets of the Agenda 2030 for Sustainable Development (Kelly et al., 2021). In order to shift current decision making and policy development to frameworks where the ocean and the services it provides to humans are considered at every step, universal understanding across all aspects of society is needed (Wisz et al., 2020). This will require multiple approaches and strategies, tailored to individuals, sectors and regions that incorporate many disciplines, methods and technologies as many of the papers in this special issue highlight.

\section{A DIVERSITY OF APPROACHES TO IMPROVING OCEAN UNDERSTANDING IS KEY FOR BETTER DECISION MAKING}

This special issue brings together differing viewpoints and processes aimed at improving societal ocean understanding through a collection of ten papers. It provides a number of suggestions that, if implemented, would lead to greater access to information that is fit-for-purpose and engagement by multiple sectors. The contributions can be grouped into four themes: citizen science; science, policy and governance; outreach and education; and communication approaches. 


\section{Citizen Science}

Coordination and compilation of information on citizen science programs is often not organized across regions, making it difficult to assess their impact and effectiveness. Garcia-Soto et al. collated information on projects occurring in the North Sea and assuming similar densities of projects across coastlines, estimate the potential extent of projects across Europe and their growth through time. They conclude that uptake of emerging technologies (such as mobile phone applications) is likely to increase the number of projects and associated engagement, and that there is scope for growth in the focus of marine citizen science initiatives.

Dalby et al. investigated the motivation and barriers to engagement of participants in citizen science. They found that while citizen science has the potential to become an effective tool for monitoring and conserving marine ecosystems, understanding the limits of citizens' engagement and their ability to collect large quantities of marine data is also important.

\section{Science, Policy and Governance}

Linking science to policy and governance for supporting informed decision making and development of effective adaptation strategies requires collaborative partnerships to ensure information provided is fit for purpose. Hetherington and Philips provide a series of practical steps for improving the delivery of science into processes for informing legislative decisions and effective policy. They stress that bridging science and policy involves ongoing engagement to ensure effectiveness.

Evans et al. explore the knowledge brokering role of the World Ocean Assessment in transferring complex scientific knowledge into useable products for society and some of the associated challenges in delivering information at such a scale. They identify that wider engagement with member states, the scientific community and marine industries is needed for the codevelopment of assessment inputs with managers, regulators and holders of maritime industry and business data in order to improve future assessments.

Through the examination of three case studies where Transnational Municipal Networks (TMNs) had been used to advance the incorporation of climate change adaptation and mitigation into marine governance, Dumala et al. found that spatial identity determined the scale and innovativeness of a networks' operation. The effectiveness of strategies and actions jointly developed by networks, depend on the allocation of human resources and on the level of commitment of the involved cities in providing leadership into such processes.

\section{Outreach and Education}

There is increasing recognition of the importance of science communication in informing science literacy and policy. Arthur et al. found that publicly funded national research facilities, such as Australia's Marine National Facility have an essential role to play in shifting from the provision of traditional research activities only, to targeted education and outreach via marine education, on-board training and engagement with a range age groups, societal sectors and ocean stakeholders.

Zielinski et al. found that increased incorporation of environmental subjects in school education, including those that consider uncertainty is needed to support the development of collaborations between researchers, data managers and educators to improve overall delivery of scientific information to society. To achieve this they propose a pathway that takes advantage of the technological abilities for environmental data collection, storage and processing, global and regional research and incorporates good practices in ocean literacy and education.

\section{Communication Approaches}

Communication approaches to environmental problems are multifaceted and challenging, particularly when impacts are slow to become evident. Using lessons learned in communicating the impacts of climate change, Canfield et al. identify that sufficient training of scientists in communicating their research and framing messaging so that it can be understood and used by diverse audiences is essential for better communicating the nutrient pollution impacts and catalyzing action.

Although understanding of the need for protective measures from environmental threats and associated actions has increased, Mamzer et al. identify that there is still a need to educate the broader audience about the urgency of responding to these threats. They found that due to their specificity, that understanding of polar regions could act an indicator of current interest in sustainability and effective environmental protection.

Paterson et al. detail the development and installation of an art-science collaboration ('Catching a Wave') as a transdisciplinary approach to engaging multiple audiences with global environmental challenges. In doing so, they highlight that collaborative arts and science projects can enhance transformations in understanding and action by encouraging decision making that engages with emotion and intuition as well as cognition as a motivation behind change.

\section{CONCLUSION}

Providing society with a holistic understanding of the role of the ocean and the impacts of human activities on the services it provides is crucial in order to catalyze the behavioral change required for future sustainability. Science, communication and education need to come together via broad collaboration to apply integrated and cross-sectoral approaches to effectively share information on the ocean, the changes occurring, associated effects on communities and approaches for mitigating changes and adapting to these changes. Overall achievement of Agenda 2030 relies on the implementation of a range of multidisciplinary and innovative approaches to improving ocean understanding that leads to universal valuing of the ocean and the role it plays in sustaining a future for all.

\section{AUTHOR CONTRIBUTIONS}

All authors contributed to the preparation of the Editorial text, participated in the discussions on its form and final shape of the text. 


\section{REFERENCES}

Allison, E. H., and Bassett, H. R. (2015). Climate Change in the Oceans: Human Impacts and Responses. Science 350, 778-782. doi:10.1126/science.aac8721

Evans, K., Chiba, S., Bebianno, M. J., Garcia-Soto, C., Ojaveer, H., Park, C., et al. (2019). The Global Integrated World Ocean Assessment: Linking Observations to Science and Policy across Multiple Scales. Front. Mar. Sci. 6, 298. doi:10.3389/fmars.2019.00298

H.-O. Pörtner, D. C. Roberts, V. Masson-Delmotte, P. Zhai, M. Tignor, E. Poloczanska, et al. (Editors) (2019). IPCC Special Report on the Ocean and Cryosphere in a Changing Climate (Intergovernmental Panel on Climate Change).

IPCC (2021). "Summary for Policymakers," in Climate Change 2021: The Physical Science Basis. Contribution of Working Group I to the Sixth Assessment Report of the Intergovernmental Panel on Climate Change. Editors V. Masson-Delmotte, P. Zhai, A. Pirani, S. L. Connors, C. Péan, S. Berger, et al. Cambridge: Cambridge University Press. (In Press).

Kelly, R., Evans, K., Alexander, K., Bettiol, S., Corney, S., Cullen-Knox, C., et al. (2021). Connecting to the Oceans: Supporting Ocean Literacy and Public Engagement. Rev. Fish. Biol. Fish. 10, 1-21. doi:10.1007/s11160-020-09625-9

United Nations (2017). The First Global Integrated Marine Assessment. World Ocean Assessment I. Cambridge: Cambridge University Press.
Wisz, M. S., Satterthwaite, E. V., Fudge, M., Fischer, M., Polejack, A., St. John, M., et al. (2020). 100 Opportunities for More Inclusive Ocean Research: Cross-Disciplinary Research Questions for Sustainable Ocean Governance and Management. Front. Mar. Sci. 7, 37. doi:10.3389/ fmars.2020.00576

Conflict of Interest: The authors declare that the research was conducted in the absence of any commercial or financial relationships that could be construed as a potential conflict of interest.

Publisher's Note: All claims expressed in this article are solely those of the authors and do not necessarily represent those of their affiliated organizations, or those of the publisher, the editors and the reviewers. Any product that may be evaluated in this article, or claim that may be made by its manufacturer, is not guaranteed or endorsed by the publisher.

Copyright (c) 2021 Zielinski, Evans and Seys. This is an open-access article distributed under the terms of the Creative Commons Attribution License (CC BY). The use, distribution or reproduction in other forums is permitted, provided the original author(s) and the copyright owner(s) are credited and that the original publication in this journal is cited, in accordance with accepted academic practice. No use, distribution or reproduction is permitted which does not comply with these terms. 